\title{
El yo-autor-escritor contemporáneo
}

Everton Vinicius de Santa ${ }^{1}$

\begin{abstract}
La gente dice que lo que importa en la vida no es lo que sucede, sino lo que piensas que sucede. Pero, evidentemente, esa definición no sirve de mucho. Es muy posible que el acontecimiento central de tu vida sea algo que no ha sucedido o algo que crees que no ha sucedido. De lo contrario, no habría necesidad de ficción y sólo habría memorias e historias, legajos clínicos; con lo que ha sucedidocon lo que realmente te sucedió y lo que crees que ha sucedido - sería suficiente.
\end{abstract}

Geoff Dyer ${ }^{2}$

En el contexto de la industria cultural en que nos hallamos inmersos, en una situación en la que cada una de las inscripciones que realiza el escritor, el intelectual, el artista en general, son transformadas en objetos de consumo para el beneficio de un otro, un tercero, y no del creador, nos permitimos preguntar ¿cuál es el papel del escritor dentro de este universo de la des-información, de la vida inventada? La identidad autorial está atrapada en un océano de otras identidades que le obliga a exhibirse para no acabar diluido bajo otras tantas informaciones, bajo otros perfiles, otros "yos". El escritor de hoy puede temer, y con razón, su desaparición justamente por hallarse más que inmerso, una vez que su identidad puede perderse en el ciberespacio. Su respuesta es intentar, al máximo, aportar su contribución y dejar su huella, aunque poco expresiva, pero que puede garantizar su imagen en este colectivo imaginario contemporáneo. Lo que traigo aquí es una reflexión en la cual el escritor de hoy se caracteriza por tener esta naturaleza singular y que se preocupa con sí mismo y su huella en la Red.

A mí me gustaría aclarar al lector, antes de todo, la distinción entre escritor y autor que llevo a cabo en estas reflexiones. Entiendo el escritor como una entidad física, la persona empírica, el actor en la escena literaria, y el autor como un órgano institucional literario determinado

\footnotetext{
${ }^{1}$ Doctor en literatura y docente del Instituto Federal de Santa Catarina (IFSC), Criciúma, SC, Brasil. E-mail: evertonvs9@gmail.com.

${ }^{2}$ Apud Frésan (2014).
} 
por su discurso, seguro y consolidado por su función textual y permeado por el contexto histórico en el que se inserta. Es como si el escritor individuo estuviera en una dimensión exterior a la obra y el autor, en un movimiento inverso, interno a la misma. El autor, por ende, se trata de una persona creada por el escritor, una postura que él asumió, de manera que su trabajo puede tener algún sentido estético, para que pueda consolidarse como activo en el campo literario. El artificio de la creación de una personalidad individual al autor (que perfectamente puedo llamar persona) no es una estrategia innovadora.

En el escenario contemporáneo, el escritor crea el autor y no al revés. El escritor, "l'écrivant", según Roland Barthes (2010), es el que va a dar vida a la instancia conocida como autor, como el personaje-escritor de memorias y autobiografías, por ejemplo. Esto se puede ver en las declaraciones o entrevistas concedidas por escritores que, en algunos casos, revelan de dónde viene la historia que ha dado vida a la obra, como un punto de referencia, un hecho o una experiencia. En otros casos, las referencias están entre líneas y es aquí que lo sucedido gana vida y en donde se inicia el juego entre realidad y ficción, un juego que está a medio camino entre el lector y el escritor en su intento para dibujar una imagen personal y publica al mismo tiempo. Hay una búsqueda por lo que es realmente real en escena, y no sólo en la literatura:

Una de las manifestaciones de esa "sed de veracidad" en la cultura contemporánea es el ansia por consumir chispazos de intimidad ajena. El pleno auge de los reality-shows, el espectáculo de la realidad tiene éxito: todo vende más si es real, aunque se trate de versiones dramatizadas de una realidad cualquiera. Como dos caras de la misma moneda, el exceso de espectacularización que impregna nuestro ambiente tan mediatizado va de la mano de las distintas formas de "realismo sucio" que hoy están en boga. Internet es un escenario privilegiado de este movimiento, con su proliferación de confesiones reveladas por un yo que insiste en mostrarse siempre real, pero el fenómeno es mucho más amplio y abarca diversas modalidades de expresión y comunicación (Sibilia, 2008, p. 221).

Sabemos que la Internet, como lo ha dicho Sibilia, ha modificado diversos factores con respecto a la literatura y la teoría literaria ${ }^{3}$. Parte de la literatura actual ha demostrado una tendencia al espectáculo, es

\footnotetext{
${ }^{3}$ Véase, por ejemplo, Di Rosario y Borràs (2012) y Goicoechea y Sanz Cabrerizo (2012).
} 
decir, reflexiones sobre el yo, el sí mismo, acrecida por una exposición a los medios digitales que lleva al escritor a utilizar este espacio como medio de auto-promoción y que es una práctica cada vez más común.

Además de las relaciones entre la literatura, la vida y los medios de comunicación, la pregunta que queda a ser tratada con más cuidado es precisamente la influencia de la escena exhibicionista de la contemporaneidad, basada en el mundo digital, en autores contemporáneos, a pesar del hecho de que necesitan exhibirse en los medios para autoafirmación de sus identidades, para la autopromoción de la obra literaria y para dejar su huella en la Red.

Es decir, hay elementos narrativos basados en la inmersión de este autor empírico en el mundo virtual como la narración en primera persona y referencias directas al lector, así como temas relacionados con su vida privada $y$, por lo tanto, se puede decir que la literatura actual es una literatura del "yo". No es nada nuevo, pero hay una tendencia frecuente en las narrativas de hoy. Al mismo tiempo, el lector "voyeur", ahora más cerca del escritor, quiere saber de dónde viene la historia que se cuenta, quiere penetrar la privacidad ajena y la del escritor, pero ese juego, ese movimiento, suscita otras cuestiones:

En otras palabras, hasta qué punto la información tal como biografía, personalidad y apariencia del autor influye en cómo se lee, y en qué medida el proceso de la escritura, y todo lo que implica, se inserta en la propia obra. ¿La ficción es una mentira, o será siempre todo verdad? (Saavedra, 2012, nuestra traducción).

Efectivamente, percibo que hay un comportamiento sintomático y propio de algunos escritores de literatura actual que tiende estar basado en el espectáculo, en el acto de ser visto y, por eso, las informaciones personales intrínsecas en el texto acaban por hacer de la literatura actual una literatura intimista y quizá confesional, aunque sea poco importante la veracidad sobre el que se escribe. Hay una relación directa entre la literatura actual y el escritor espectacularizado, favorecida por una hibridación de los modos de publicación tradicionales con los medios digitales. Es decir, estos medios (impreso y digital) son espacios híbridos porque el escritor y el lector de hoy ya no están sólo sujetos al papel impreso, sino que sus relaciones se maximizan por y en los ambientes digitales, que promueven una pequeña distancia entre el escritor y su lector. 
Por lo tanto, la falta de distancia muestra una relación indisoluble de contagio entre la práctica literaria y los medios digitales, especialmente para estos autores cada vez más mediatizados y espectacularizados. Lo que se observa es el intento de una construcción de una identidad autorial en el espacio digital por medio del exhibicionismo en las redes sociales donde de promueve un juego de auto-promoción y popularidad, aunque se publique en el medio impreso. Los dos medios son complementarios en la construcción de esta imagen pública del escritor, sobre todo en perfiles sociales, blogs, páginas web, entrevistas y publicaciones no literarias, así como también en periódicos y la participación en actividades académicas.

Así, la relación dialógica entre la realidad y la ficción ha sido explotada desde hace mucho tiempo y ha marcado el panorama actual del siglo XXI, precisamente porque se ha convertido en una tendencia cada vez más intrínseca a la literatura y cuyas fronteras son cada vez más diluidas. Este paso al medio digital parece que está haciendo de la figura del autor en nuestros días una figura cada vez más pública. En el contexto brasileño me refiero a nombres como Daniel Galera, Luis Ruffato, Carola Saavedra, João Almino, Adriana Lisboa, Cristovão Tezza, entre muchos otros pertenecientes a una generación actual y productiva. De hecho, la reacción por parte del escritor es su desenfrenada espectacularización dentro y fuera de la Red.

\section{Dilemas del yo-autor-escritor y las ego-historias}

De hecho, la imagen de un autor no es sólo el producto de la obra de un autor: se desarrolla en la confluencia de sus acciones y palabras, por una parte, y las palabras de los que, de diferentes maneras y según sus intereses, contribuyen a su formulación. A menudo la imagen de un autor está especialmente formulada después a través de terceros, cuando el escritor muere (Maingueneau, 2013, p. 18, nuestra traducción).

La imagen del autor está directamente relacionada con la mirada del otro en sí mismo, una imagen transmitida por él mismo y dada a conocer en el espacio de los medios sociales cuyas identidades se mezclan con el escritor mientras que se puede inventar una identidad para satisfacer los propios intereses del autor o de las editoras en el juego literario contemporáneo que han individualizado cada vez más a los escritores y han dado importancia a la publicidad de su imagen autorial. 
Con la literatura afectada por los medios digitales, el escritor constituye una operación estratégica, retórica y poética, que escala su comportamiento dentro y fuera del texto en la construcción de una imagen ahora espectacularizada. Esta imagen del autor y del escritor llegó a ser tan híbrida como el propio entorno en el que se encuentran. Si "esta noción constituye el momento fuerte de la individualización en la historia de las ideas, de los conocimientos, de las literaturas, en la historia de la filosofía también, y en la de las ciencias" (Foucault, 2005, p. 6), entonces esto gana fuerza en la cuestión de la individualización, pero una individualización destinada a la difusión de su propia imagen, sus propias ideas y deseando una retroalimentación sobre lo que se escribe.

La autenticidad y el valor del autor nunca han sido fuertemente impulsadas por un sistema literario que hoy se distingue por esta individualización pública de la imagen del autor, es decir, el tipo que escribe no deja de desaparecer debido a la subjetividad del lenguaje, como Foucault también mencionó. Sobre la supresión del autor en una "relación de la escritura con la muerte", para él:

esta relación de la escritura con la muerte se manifiesta también en la desaparición de los caracteres individuales del sujeto escritor; por medio de todos los traveses que establece entre é1 y lo que escribe, el sujeto escritor desvía todos los signos de su individualidad particular; la marca del escritor ya no es sino la singularidad de su ausencia; le es preciso ocupar el papel del muerto en el juego de la escritura (Foucault, 2005, p. 8).

La muerte del autor aquí se relaciona con la desaparición de los caracteres individuales del escritor tema, el nombre en sí, sobre todo porque la escritura, para él, tiene esta relación con la inmortalidad. Con excepciones, la desaparición del autor no puede ser descartada como una categoría porque está asociada directamente a la noción de trabajo, la unidad y luego a la "función de autor", es decir, el nombre del autor no es sólo un elemento más en el texto. Hay un juego en esta relación con el discurso literario y es esta función de categorización que permite definir, agrupar, excluir y oponerse a los otros textos. El nombre del autor permite este movimiento interno y externo al discurso en el cual se hace este discurso una "palabra de inmediato" consumible por una cultura determinada. Por lo tanto, para Foucault (2005, p. 16), "la función autor es pues característica del modo de existencia, de circulación y de funcionamiento de ciertos discursos en el interior de 
una sociedad" y, en la cultura determinada de hoy, esta función está basada en el espectáculo, en "una sociabilidad líquida a la cultura somática de nuestro tiempo" (Sibilia, 2008, p. 28).

En el espectáculo del escritor, o de la autoría, es importante saber que entiendo aquí como siendo este escenario mediático que está alrededor del escritor, un contexto que ha contribuido a la construcción de esta imagen autorial alimentada por la cultura del espectáculo y por estrategias editoriales que puso el escritor en este espacio público, lo que le permite, al escritor y al editor, controlar lo que se desea proyectar al público. Esta construcción de una imagen del autor es también parte de la constitución de una identidad literaria que el propio escritor crea de sí mismo para mostrar a su público. En este caso, en esta construcción de una imagen del autor, se puede hablar de "la postura del autor", o incluso sobre la creación de una "persona", según Meizoz (2007, p. 17):

La postura constituye la "identidad literaria" construida por el autor mismo y, en la mayoría de los casos, retomada por los medios, quienes la ponen a disposición del público. Dicha noción no coincide sino en ciertos aspectos con la de "figura del autor" estudiada por Maurice Couturier, ya que el análisis que éste propone se restringe únicamente a las lógicas textuales. Podríamos también convocar la noción latina de persona utilizada en el teatro para designar la máscara; ésta instituye tanto la voz como su contexto de inteligibilidad. En la escena de enunciación de la literatura, el autor sólo puede presentarse y expresarse provisto de su persona, de su postura. No olvidemos que en su obra el autor construye una imagen de sí mismo para el público. En el caso de Proust, ésta substituye metonímicamente al autor. Así, la obra constituye, para la posteridad, una representación estable de ese ser perecedero que es el autor: "[...] aquello que sale de mí y me representa".

Esta postura literaria o este personaje creado por el escritor cae en la formación de lo que entendemos por el autor en la construcción de su imagen pública y que opera en las fronteras exteriores del texto y en el contexto, como señaló Foucault (2005) y que retoma Maingueneau. Maingueneau se propone a distinguir la imagen del autor en tres valores distintos que me ayudan a aclarar esta noción del autor espectacularizado:

La primera, la más clara en un sentido dado, es la del "responsable": aquel que responde por un texto, que asume su responsabilidad. Esta acepción no tiene nada de específicamente 
literario, ya que "ser el autor de un texto" vale para cualquier texto. [...] De acuerdo con la segunda acepción, el autor designa al actor de la escena literaria ("escritor", "hombre de las letras", "literato"...). Se refiere a los estatus socialmente identificados que están vinculados a ciertas representaciones estereotipadas variables históricamente. En la tercera acepción, el autor es el correlato de una obra, lo que propongo llamar "autor", identificable en el paisaje mediático, encontrado en los tesauros ("los grandes autores") cuando alcanza la consagración (Maingueneau, 2013, p. 15, nuestra traducción).

Por lo tanto, estamos tratando aquí del escritor, del autor y de la persona como instancias presentes y ausentes en el texto literario autoficcional y activas en este espectáculo de la creación, donde las vertientes de los géneros de la actual subjetividad contemporánea es en donde los sujetos muestran sus "yos" en Red, caracterizando parte de la literatura actual como una literatura de la auto-promoción y de la autorepresentación. Por lo anterior puedo hablar en meta-literatura.

La imagen del autor en los medios de comunicación, este espectáculo del escritor presente e involucrado en este "espacio biográfico", se articula y experimenta con una amplia gama de géneros vinculados a estas experiencias de la vida, a este discurso en primera persona, a relatos personales y por lo tanto, a un consentimiento a esta invasión de la privacidad y a la exposición de la intimidad que hizo del "autor contemporáneo accesible a todos" (Lejeune, 2014, p. 229). Todo esto está en línea con las ego-historias, un ejercicio de autoficción en el que se habla de sí mismo:

vemos ejercicios de "ego-historia", un auge de autobiografías intelectuales, una narrativa autorreferencial de la experiencia teórica y la autobiografía como sujeto de la investigación en sí, por no hablar de la pasión por los diarios de filósofos, poetas, científicos, intelectuales. $Y$ tenemos que decir que, a veces no hay muchas diferencias de tono entre estos ejercicios de la intimidad y de la intromisión en las vidas famosas $u$ ordinarias con las que se enfrentaba la televisión todos los días (Arfuch, 2010, p. 61, nuestra traducción).

El concepto de "ego-historias" fue un término utilizado por Pierre Nora, en 1987, en su "Essai d'ego-histoire", y para mí las ego-historias no son ni una autobiografía falsamente literaria, ni confesiones 
innecesariamente íntimas, ni intentos de un análisis psicoanalítico de un "yo". El ejercicio de las ego-historias es tratar su propia historia como si se tratara de la historia del otro, tratando de aplicársela a sí mismo.

Debemos hablar también de una deslegitimación de la figura del autor, es decir, la pérdida del aura mítica relacionada con el oficio de escritor. De hecho, el escritor está cada vez más presente en los medios de comunicación y cada vez más en esta cultura mediática que explora su imagen. El resultado es un juego que implica escritores, lectores, editores y medios de comunicación físicos y virtuales alrededor del objeto literario (esta reflexión se puede extender a otras formas de arte diferentes a la literatura, por ejemplo) y de la figura pública del escritor, un efecto o reflejo de un contexto actual en el que el escritor está presente todo el tiempo, mientras el lector espera tener contacto con este escritor aunque sea indirectamente, es decir, el escritor debe mantenerse actuante en la red tanto como su obra y estar disponible para la interacción, para el diálogo, y esto es lo que ha alimentado la industria de la cultura de hoy.

La cultura de tecnoespetáculo valora al productor de la imagen en lugar de la imagen del producto. La tendencia de las ego-historias, de la escritura de sí misma en la cultura contemporánea, se justifica porque en la otra cara de la moneda está el interés del público lector acerca de quién habla de sí mismo, ejemplo del éxito de las redes sociales, de las autobiografías, de los blogs y de las memorias. Hay una polarización entre exhibicionistas y observadores que alimentan esta escena literaria.

El fenómeno del tecnoespectáculo es cada vez más destacado entre los escritos literarios contemporáneos, hasta el punto en que la figura espectacularizada del escritor invade los textos autobiográficos:

Se ha vuelto habitual recurrir a los imaginarios ficcionales para tejer las narraciones de la vida cotidiana, lo cual genera una colección de relatos que confluyen en la primera persona del singular: yo. En años recientes, sin embargo, las narrativas de ficción parecen haber perdido buena parte de su hegemonía inspiradora para la autoconstrucción de los lectores y espectadores, con una creciente primacía de su supuesto contrario: lo real (Sibilia, 2008, p. 223).

Más que las narraciones de la vida cotidiana y más que solamente un relato confesional, las "memorias intelectuales" están basadas en la vida profesional de un sujeto "yo" real, generalmente preocupado más con su vida de formación académica, o profesional, que con la biografía 
tradicional de vida, caso de Cristovão Tezza, escritor brasileño, ex profesor universitario, quien muestra en sus últimas narrativas una tendencia a la autoficción, con especial atención a la narrativa $O$ espírito da prosa: uma autobiografia literária (2012), ${ }^{4}$ y también el caso de Rodrigo Frésan, escritor y periodista argentino, quien hizo un juego muy interesante en La parte inventada (2014), una novela metaliteraria sobre el oficio del escritor. Sobre estas dos narrativas es que sigo mis reflexiones.

\section{Manipulando verdades}

El escritor de hoy es un escritor tecnoespetacularizado, o sea, presente en pantallas y presente en la Red, rodeado por la avidez en "hacerse visible", por la necesidad de mantener contacto directo con sus lectores para preservar su imagen, la visibilidad y la valoración de los spotlights, caracterizando el panorama literario actual del espectáculo. Como ejemplo de los dos escritores que traigo a la discusión, Cristovão Tezza y Rodrigo Frésan, los dos tienen páginas en la $\operatorname{Red}^{5}$ o escriben para periódicos. Estoy, desde luego, utilizando la idea de Guy Debord, en "La sociedad del espectáculo", publicada en 1967, una vez que está directamente relacionada con una sociedad de consumo organizada en torno a la producción y consumo de imágenes que revelan formas actuales de construir la subjetividad con otras modalidades de relatos sobre sí:

El concepto de espectáculo unifica y explica una gran diversidad de fenómenos aparentes. La diversidad y contrastes de éstos son las apariencias de esta apariencia organizada socialmente, que debe ser ella misma reconocida en su verdad general. Considerado según sus propios términos, el espectáculo es la afirmación de la apariencia y la afirmación de toda vida humana, es decir social, como simple apariencia. Pero la crítica que alcanza la verdad del espectáculo lo

\footnotetext{
${ }^{4}$ El texto aún no tiene traducción al castellano.

5 Sobre Tezza véase en: su página personal, <www.cristovaotezza.com.br>; su columna en el periódico Gazeta do Povo con publicaciones hasta 2014, <www.gazetadopovo.com.br/vida-ecidadania/colunistas/cristovao-tezza/>; y su columna reciente en el periódico Folha de S. Paulo, con publicaciones actuales iniciadas en 2017, <www1.folha.uol.com.br/colunas/cristovao-tezza/>. Sobre Fresán véase en: su blog personal, sin actualizaciones desde 2005, <rodrigofresan.blogspot.com.br>; sus artículos en el periódico español El País, con publicaciones hasta 2014, <elpais.com/autor/rodrigo_fresan/a>; y su columna en el periódico peruano El Comercio, con publicaciones del escritor hasta finales de 2016, <elcomercio.pe/noticias/rodrigo-fresan-524844>.
} 
descubre como la negación visible de la vida; como una negación de la vida que ha llegado a ser visible (Debord, 1995, p. 10).

Esta preocupación en mantener contacto con lectores y, además, mantener una presencia concreta en la Red, nos revela no solo una tendencia a la espectacularización, sino también una tendencia a los escritos sobre sí mismo. Estas prácticas están presentes en la cultura cibernética donde se observa esa exposición de "yos" y donde los escritores han utilizado tal visibilidad a su favor, un comportamiento narcisista cada vez más en boga e nuestra sociedad:

Ese registro de la voz -la primera persona, el testimonio- en tanto expresión altamente valorada de la experiencia, tanto individual como colectiva, resulta hoy imprescindible en relación, justamente, con la dimensión socio histórica de nuestro conflictivo presente. El "espacio biográfico" altera decisivamente, como ya dijimos, las esferas clásicas de lo público y lo privado para delinear una nueva "intimidad pública", tanto en su carácter modélico de "educación sentimental", ligada al despliegue subjetivo y hasta narcisístico, como en la dramaticidad del vivir y la elaboración testimonial de memorias traumáticas (Arfuch, 2014, p. 70).

Es posible pensar estas dos narrativas a partir del concepto de "egohistorias" que trata del texto literario en primera persona en el cual el autor nos cuenta sus experiencias personales en las que se refiere a su vida profesional y personal como una biografía. En estos textos se observa la substancia biográfica presente en estos escritos y que pueden desvelarse en grados de ficción (como diría Barthes en "El grado cero de la escritura", de 1953) toda vez que las ego-historias son también una autoficción donde se observa un juego entre realidad y ficción. Las egohistorias representan un tipo de autobiografía intelectual caracterizada por una conexión íntima y personal que estos escritores mantuvieron con sus elecciones teóricas, conceptuales y profesionales.

Más que la construcción de un sujeto teórico tradicional, en estos discursos, o sea, en las "ego-historias", sus autores transforman la teoría en discurso narrativo y utilizan la escritura autorreferencial con situaciones y personajes no siempre inventados, para explicar sus identidades, sus roles sociales e institucionales, sus transformaciones personales y artísticas. Son estrategias que corroboran la idea del espectáculo en parte de la literatura actual: 
Los ego-escritos y sus autores, para transformar la teoría en la narrativa y entender la autobiografía como una posible invención del "yo" en el discurso narrativo, permiten la fusión teórica con el objeto y calienta el debate sobre el vínculo entre sus ideas particulares y el pensamiento contemporáneo. Además, mediante el uso de la escritura de ficción - pero no con situaciones y personajes inventados - explican el carácter constructivo de nuestra identidad, reflexionan sobre sus roles sociales e institucionales, exponen sus propias perplejidades ante sus transformaciones. (Leiroz, 2008, p. 2, nuestra traducción).

La exposición pública por medio de la escritura de ficción, segundo nos dice Leiroz, es una estrategia presente en las narrativas de Tezza y Frésan, dos auto-ficciones en las cuales se percibe las características de las ego-historias.

Puedo decir que la página personal de Tezza en Facebook me parece una vitrina de autopromoción de sus escritos o de eventos en los cuales participará. Además, hay muchos links para publicaciones sobre él mismo. Aunque no se pueda saber si el propio Tezza es quien escribe las publicaciones en la red social, seguramente se puede percibir el uso de la Red como objeto de experimentación, donde los seguidores pueden comentar y hacer preguntas, o sea, el contacto con el autor 6 alimenta este juego entre el escritor y sus lectores. En el blog, hay informaciones sobre su biografía, publicaciones y algunos textos críticos. Además, Tezza es escritor de una columna en un periódico brasileño, la "Gazeta do Povo", donde publica crónicas y textos de otros géneros todos los martes. ${ }^{7}$

Rodrigo Fresán utiliza las mismas estrategias de que Tezza. Tiene su página en Facebook ${ }^{8}$ donde hay publicaciones suyas, links para textos que publica en otras páginas o en su blog y el contacto con sus lectores es constante. Ellos pueden comentar sobre las publicaciones porque es un perfil abierto. Su blog es más activo que la página en el Facebook ya que allí Fresán publica más y, además, incluye textos más críticos y no solamente links de otros textos. Lo que se observa es que la página del

\footnotetext{
${ }^{6}$ En la página se puede leer “Cristovão Tezza - autor”: <www.facebook.com/CristovaoTezza >. Acceso en: 5 mayo 2017.

${ }^{7}$ Véase en: <www.gazetadopovo.com.br/vida-e-cidadania/colunistas/cristovao-tezza/〉. Acceso en: 5 mayo 2017.

${ }^{8}$ Véase en: <www.facebook.com/pages/ Rodrigo-Fresán-16585353486>. Acceso en: 5 mayo 2017.
} 
Facebook no se actualiza desde 2012, pero desde la publicación de "La parte inventada", a menudo se encuentra textos críticos sobre la narrativa ${ }^{9}$ en otros medios, sobretodo en periódicos.

Tomando todo en consideración, lo que se puede decir es que estos son solo algunos ejemplos de estrategias de autopromoción que otros escritores de hoy llevan a cabo para promover su imagen pública, para dejar sus huellas en la Red y para que puedan mantenerse activos e visibles.

\section{Sobre los autores y sus narrativas}

A mí me gustaría tratar rápidamente de dos narrativas de estos dos autores, Tezza y Fresán, que propuse utilizar como ejemplo en estas reflexiones apuntando algunos elementos, no todos, que me ayudarán a aclarar los puntos teóricos sobre la construcción de la persona y de la figura pública del escritor sobre los cuales he tratado aquí.

Empiezo hablando de la narrativa $O$ espírito da prosa, de Cristovão Tezza. Profesor universitario y escritor, esa autobiografía literaria fue publicada en 2012. Narrada en primera persona, Tezza relata su vida de profesional en las letras y cómo empezó a escribir. De hecho, por haber sido profesor en la universidad por algunos años, la narrativa tiene marcas propias de un estudioso catedrático, un lenguaje característico y referencias de alguien familiarizado con el mundo académico.

Tezza, el narrador, está justificando acontecimientos de su vida en la academia y se aleja de su vida personal como se esperaría de una biografía tradicional. O espírito da prosa más que un diario, es un registro de una vida intelectual, no sólo de una vida íntima, que casi nos pasa desapercibida. Son memorias intelectuales de un escritor ya no tan joven. Él escribe sobre sus clases en la universidad, sobre las teorías que influyeron en sus trabajos académicos y también sobre su producción literaria. Además, todo el tiempo, interrumpe la narrativa para hacer autocríticas o para aclarar algún punto teórico sobre el cual trata en su biografía.

En 44 capítulos, Tezza construye una imagen de sí mismo, de su persona, intentando crear una imagen de autor que permite a los lectores conocer su "yo" intelectual, siempre focalizándose en puntos de vista teóricos sobre su vida profesional y no en acontecimientos de su vida personal. Esa es una característica de las ego-historias, o sea, el escritor

\footnotetext{
${ }^{9}$ Véase Pron (2014) y Geli (2014).
} 
en primera persona construyendo una experiencia utilizando la memoria, fabulando la historia e reinventando su propio "yo", manipulando verosimilitudes.

La narrativa se hace gradualmente interrumpida para dar paso a los comentarios con respecto a la teoría y las lecturas relacionadas con la práctica literaria, asertivas bien estructuradas que demuestran su compromiso con los orígenes del Tezza escritor y del Tezza profesor. Durante toda la narrativa, el narrador-autor habla con el lector, no porque Tezza lo subestime, sino porque, de hecho, Tezza describe en su texto el "espírito da prosa" que está en el título de la narrativa.

Desde el gran éxito de O filho eterno (2007), tal vez su narrativa más importante hasta hoy, Tezza ha construido su propio camino y proyecto literario el cual culminó en O espírito da prosa, una narrativa crítica, reflexiva y ensayística sobre su propia producción en su carrera, se observa, además, un escritor que sabe utilizar algunas estrategias de autopromoción.

Los medios de comunicación también han contribuido al proceso de exhibición de un escritor que ha encontrado en el lenguaje de su autobiografía literaria un ejercicio de autoexamen que puede interesar a los lectores más curiosos, especialmente al lector técnico, investigador o académico. Tezza admite su percepción de la transición que tuvo lugar entre los medios digitales, al verse indisolublemente involucrado e infectado por estos cambios:

Este es otro rompecabezas sobre el adviento de la Internet - se popularizó la palabra de una manera nunca antes vista en otro momento de la historia; no hay ninguna página web sin ninguna palabra escrita ni ningún requisito ni cualquier invitación para que usted pueda escribir algo, y siempre algo familiar, intransferible, cerca; a pesar del poder increíble de las imágenes increíble en Internet, la palabra sobresale sobre ella misma. Sin embargo, en una paradoja, el historial del pasado se hizo extremadamente volátil (Tezza, 2012, p. 163, nuestra traducción).

La volatilidad sobre la cual afirma Tezza está directamente relacionada con la naturaleza de los ambientes digitales que dan forma a un espacio aparentemente ilimitado para el archivamiento de memorias, registros e imágenes, el territorio de "libre" acceso y que ofrece oportunidades que otros medios no podían garantizar en tiempos pasados.

El mismo ambiente que asegura (aunque falsamente) la idea de una imagen eterna de un yo presente en el mundo es el mismo que pone en 
duda la supervivencia de la imagen espectacular alimentada por la mirada del "otro". Las memorias registradas allí a través de la palabra configuran la fuerza que mueve la transposición de la memoria (cuando ocurre) a la pantalla o al papel. Como nos ha dicho Tezza (2012, p. 164, nuestra traducción), "vivimos rodeados por un muro permanente de las palabras escritas, la memoria de nuestra vida personal ha retrocedido a la lógica de la oralidad; nuestros pasos se borran todos los días en la arena y sólo pueden hacerse de nuevo por el frágil y falso recuerdo interesado".

En la literatura actual, como lo hace Tezza en otras narrativas, es necesario considerar un sujeto-escritor que reconstruye su identidad a través del lenguaje y tiene, de hecho, en la memoria y en los escritos sobre el mismo el punto de referencia para la revitalización de la misma. Tezza escritor se muestra para el "otro" en el juego con el lector, un movimiento que camina entre los espacios de la voz del narrador y del autor presente en una narrativa que va más allá de lo biográfico:

Es decir simplemente: si el lector acepta que las palabras que lee ahora son la expresión directa y intransferible de las opiniones de Cristovão Tezza, él mismo, aunque confusas o engañosas, él no se enfrenta a una no-novela, una no-ficción (un ensayo o cualquier género de texto que saca todo su significado a partir de la suposición intencional y directa de la verdad). Pero si el lector percibe en estas palabras que hay otro que habla (un narrador abstracto, por ejemplo), con la intención estética (es decir, com la intención de desarrollar una narrativa cerrada por la representación de un punto de vista que no es necesariamente ni completamente la de CT; que, en definitiva, no puede ser lapidada por el autor), que se encuentra delante de la prosa novelística, aún embrionaria (Tezza, 2012, p. 15, nuestra traducción).

Tezza está siempre presente en eventos literarios, publicando textos en periódicos, concediendo entrevistas, tiene un sitio personal en la web, un perfil en el Facebook ${ }^{10}$ y tiene contrato con una gran e influyente editora brasileña, la Record, que también está siempre explotando su imagen ${ }^{11}$. Aquí está la parte que más me interesa y que se refiere a los medios digitales como soporte a la construcción de una imagen autoral con la intención de crear y vender una imagen pública y revelando una

\footnotetext{
${ }^{10}$ Véase en: <www.facebook.com/CristovaoTezza〉. Acceso en: 5 mayo 2017.

${ }^{11}$ Véase en: <www.record.com.br/autor_sobre.asp?id_autor=928>. Acceso en: 5 mayo 2017.
} 
de las grandes ventajas del escritor de nuestros tiempos: la Internet como medio de propaganda, de exhibición. Y Tezza lo sabe:

Periódicos y revistas importantes me invitaron a escribir crítica, reseñas de libros, crónicas; Fui entrevistado innumerables veces; mucho se ha dicho sobre mi escritura; llegué a ser traducido a seis o siete idiomas; periodistas, críticos y profesores continúan compartiendo con simpatía mis libros, y estoy agradecido con ellos, después de todo, por garantizar mi supervivencia (en el sentido abstracto, como artista, y en el sentido concreto, como respaldo de la familia) (Tezza, 2012, p. 10, nuestra traducción).

Observamos en la narrativa de Tezza, cuando vemos en la portada "autobiografía literária", la figura de un escritor no solamente exacerbado, sino también del intelectual, como esperamos ver en las "ego-historias" de los profesionales de las Letras. Tezza es también el sujeto-escritor que está en la escena literaria contemporánea de la cual hace parte y que tiene su importancia haciendo reflexiones o autoanalizándose, considerando las condiciones de sus lectores y de la propia literatura del siglo XXI. Esta literatura exige otra mirada de los escritores en sus escritos, otras formas de ver, otros temas que nos muestren más su artesanía estética.

En relación con la artesanía estética y los proyectos literarios, me gustaría hablar sobre la primera narrativa del proyecto de Rodrigo Fresán, La parte inventada (2014), ya he considerado escribir otro ensayo analizando la segunda y tercera narrativas de la trilogía que se ha publicado recientemente, La parte soñada (2017), y La parte recortada, todavía será publicada. En este proyecto, Fresán intenta explotar y explicar cómo funciona la mente de un escritor, intentando poner en escena estrategias manifiestamente autoconscientes de producción textual y la ética del oficio. Voy a detenerme en algunos puntos de La parte inventada para que podamos ver ahí algunos elementos relacionados a las "ego-histórias" que, además, explicitan muy bien las estrategias de autopromoción en la trilogía de Fresán.

La parte inventada (2014) es una narrativa distinta la del Tezza, sobre todo, porque tiene una tesitura más ficcional y menos confesional. Quiero decir que Frésan juega más con el lenguaje, tal vez no solamente por no tener el mundo de la academia en su pasado, como Tezza, sino también porque su propuesta es distinta la del Tezza, aunque próxima. 
Frésan construye una monumental obra de 566 páginas basada en una pregunta: “¿Cómo funciona la mente de un escritor?”. No hay sólo memorias intelectuales como se observa en la narrativa de Tezza, sino también memorias personales. El juego que hace Frésan está protagonizado por "El Escritor", un personaje que tiene consciencia de su lector y de su realidad en tiempos de Internet:

A los lectores electrocutados de ahora, acostumbrados a leer rápido y a leer breve en pantallas pequeñas, $\mathrm{Y}$, sí, adiós, a todos ellos, al menos por el tiempo que dura y dure este libro. Desenchufarse de fuentes externas para sólo alimentarse de electricidad interna. Y ésa es - warning! warning! -, al menos en principio y en el principio, la idea aquí, de aquí en más, están advertidos (Frésan, 2014, p. 18).

Se nota, en toda la narrativa, un registro cargado de infinitas reflexiones personales sobre el yo que nos habla y referencias culturales, de Vonnegut a Batman, de Pink Floyd a Hichtcock, una prosa lenta, muy parecida al estilo de Marcel Proust. Frésan ha escrito una obra de potencia, a contramano de las especulaciones editoriales, de la proliferación de textos cortos, rápidos y contrario a una especie de autoritarismo que se produce en la Red sobre la producción de una literatura para seudolectores. Frésan está preocupado con su oficio como escritor y explota eso en su narrativa confesional, dejando más marcas personales e inventando un "yo" teórico, ficticio, con personajes inventados y mezclando vida y ficción, aunque se trate de una biografía intelectual disfrazada de ficción: "la piedra que arrojamos desde aquí, desde el excéntrico presente. La piedra es la causa y sus ondas el efecto: lo que se cuenta a partir de lo sucedido, la historia antes y detrás de la Historia. La piedra es la parte inventada que, enseguida, pasa a formar parte de la verdad" (Fresán, 2014, p. 53).

En la primera parte de libro, el narrador que nos acompaña (antes presentado como "El narrador"), nos presenta a "El niño", muy probablemente una alusión al propio Fresán escritor, en su trayectoria hacia tornarse escritor libros, el que se nota por medio del lenguaje en tercera persona, diferente del que hace Tezza pues aquí no estamos delante de una autobiografía declarada, sino memorias ficcionalizadas de un sujeto que se dice escritor y que se propone a contarnos su vida y su oficio: ese escritor que siempre seguirá siendo ese niño se preguntará a sí mismo "cómo es que nunca le preguntan algo muy más importante, o, al menos, más interesante, que 'Cómo se le ocurren esas ideas que 
escribe?'. Por qué nunca le preguntan: ‘Cómo se le ocurrió la idea de ser escritor?'" (Fresán, 2014, p. 54).

En toda la narrativa el narrador nos va situando sobre la vida de "El escritor", como en un diario sobre hechos de la vida, pensamientos, personas con quien te has cruzado en la vida, al mismo tiempo que llama la atención del lector con reflexiones sobre el oficio del escritor, como Tezza lo hace, aunque con otro objeto ya que Tezza no intenta reflexionar sobre el oficio del escritor sino demostrar cómo, de hecho, ha sido su vida profesional. Fresán va más allá, es más ficcional que confesional, y percibimos que la construcción del tu - yo escritor se muestra en la narrativa cuando se observa la presencia de "El Chico" y "El Narrador" en diálogos constantes, siempre juntos, como si quisiera evidenciar la presencia de la pulsión literaria desde siempre:

'No me cuesta escribir. Me cuesta sentarme a escribir', declaraba El Escritor en una de las entrevistas televisivas que El Chico y La Chica habían recopilado. Y EL Chico descubre - con una mezcla de horror y rara alegría - que tal vez comienza a odiar a El Escritor. A odiarlo por lo que dijo y por lo que escribió y por cómo vivió y por cómo desapareció y por cómo es el responsable indirecto de la llegada de La Chica a su propia vida (Fresán, 2014, p. 225).

En los otros capítulos, el narrador nos va mostrando sus memorias de la infancia, las lecturas, su formación, sus pensamientos. Y cabrá al lector juntar los trocitos hasta desvelar el fragmentado escritor que nos habla. Las "ego-historias", desde el punto de vista de la novela de Fresán (si, novela) nos revela otra manera de hacerse visible y otra tentativa, diferente la de Tezza, en la construcción de una imagen de autor que, al fin y al cabo, se verá completa cuando la trilogía toda esté publicada y, además, en la narrativa alternativa de los aparatos digitales que nos rodean todos los días.

Por lo tanto, como ha advertido el narrador, la narrativa es densa y exige atención y dedicación de un lector no común en tiempos de Internet que solo podrá comprender todas las referencias presentes en la narrativa si, realmente, fuere un lector de los medios digitales, inmerso por las prácticas cotidianas de escritura y lecturas. Hay muchas citas y senderos que exigen más del lector, un desafío frente a las efímeras prácticas lectoras de muchos de nosotros o de muchas otras "literaturas" que se hacen en las pantallas. Así, percibimos que el proyecto de Fresán, más complejo que la narrativa de Tezza, pone al 
máximo la tentativa de construcción de una imagen autoral por medio de un lenguaje que acercase as lector de los medios digitales al mismo tiempo que espera que este mismo lector lo abandone por algún tiempo, o sea, a mí me suena como una paradoja la narrativa, pero eso se verá en análisis futuras.

\section{Imágenes del "yo" en el papel y en la pantalla}

En las dos narrativas, tanto en la de Tezza como en la de Frésan, es exactamente la compulsión por el "yo" que se sabe mediatizado y mediático, "pantallizado", lo que se observa, aunque Tezza sea más autobiográfico en el sentido tradicional y de una memoria intelectual y Frésan más ficcional, más verosímil, pero no menos confesional. Ambas narrativas son dos ejemplos de autoficciones en el que se observa la exposición aumentada del yo, a veces más, a veces menos, y que nos muestra también una persona (en el sentido etimológico de máscara), una imagen que necesita "hacerse visible".

Lo que todavía se nota en las narrativas de Tezza y Frésan, pero también en muchas otras de la literatura contemporánea, es una hibridación entre el texto literario y los medios digitales en el sentido de que el soporte digital tiene su peso en la construcción de una imagen autoral que necesita hacerse visible para que pueda vender, pero también para que sea leído. Creo que esto es un camino sin retorno. Estas reflexiones metaliterarias están presentes en la literatura del siglo XXI y, por ende, están vinculadas a la cultura digital del espectáculo, con la preocupación en crear un "yo-autor" en la tela y en el papel. En consecuencia, eso afecta al escritor y a los propios lectores:

Se promueve una intensificación y una creciente valoración de la propia experiencia vivida, responsable por el "giro subjetivo" que hoy se constata en la producción de narrativas, ya sean ficticias o no. Los cimientos de esos relatos más recientes tienden a hundirse en el yo que firma y narra. Con una frecuencia inédita, el yo protagonista, que suele coincidir con las figuras del autor y del narrador, se convierte en una instancia capaz de avalar lo que se muestra y se dice (Sibilia, 2008, p. 224).

Vivimos tiempos de literaturas híbridas. Quiero decir que lo cotidiano tecnológico está presente en el discurso narrativo e interfiere en las tramas al decir que la literatura actual es de lectura rápida y poco 
compleja (Fresán nos muestra el contrario con su narrativa monumental), y no solo porque asociamos el papel con la pantalla y vice-versa, sino también porque el lenguaje literario y la obra están en un espacio múltiple como nunca se hemos visto antes.

Por lo tanto, las estrategias de auto-exhibición implican una reflexión sobre la autobiografía, la identidad literaria y el mercado de consumo de libros. De hecho, se están consolidando nuevas funciones para los roles del lector y del escritor: el lector más interactivo, más atento, más crítico; el escritor más preocupado con su imagen pública, más en evidencia, más preocupado con un lenguaje del cotidiano, más preocupado con sí mismo. Eso todo permite que las ego-historias ganen espacio en este escenario donde la escritura literaria extrapola el vivido, y es aquí donde la espectacularización de esta imagen autoral emerge aliada a los medios digitales promoviendo la espectacularización de los escritores y de nosotros todos, aunque indirectamente.

\section{Referências}

ARFUCH, Leonor (2010). O espaço biográfico: dilemas da subjetividade contemporânea. Rio de Janeiro: Editora da UERJ.

ARFUCH, Leonor (2014). (Auto)biografía, memoria e historia. Clepsidra. Revista Interdisciplinar de Estudios sobre Memoria, Buenos Aires, n. 1, p. 68-81.

BARTHES, Roland (2010). O grau zero da escrita. São Paulo: Martins Fontes.

DEBORD, Guy (1995). La sociedad del espectaculo. Santiago del Chile: Naufragio.

DI ROSARIO, Giovanna; BORRÀS, Laura (2012). Translating digital literature: two experiences and a reflection. Texto Digital, Florianópolis, v. 8, n. 1, p. 138162. Disponible en: <goo.gl/hmkpc1>. Acceso en: 5 mayo 2017.

FRÉSAN, Rodrigo (2014). La parte inventada, Barcelona: Randon House.

FOUCAULT, Michael (2005). ¿Qué es un Autor? Buenos Aires: El Seminario.

GELI, Carles. Rodrigo Fresán: “Casi todo lo que se vincula hoy al escritor me molesta". El País, Barcelona, 2 abr. 2014. Disponible em: <goo.gl/dByWXG>. Acceso en: 5 mayo 2017.

GOICOECHEA, María; SANZ CABRERIZO, Amelia (2012). Literary Reading rituals and practices on new interfaces. Literary and Linguistic Computing, Oxford, v. 27, n. 3. 
LEIROZ, Flávia (2008). Ego-escritos: possíveis alternativas de produção teórica. In: CONGRESSO INTERNACIONAL DA ABRALIC, 11., 13 a 17 jul. 2008, USP. Anais... São Paulo: Abralic. Disponible en: <goo.gl/eSHVdT>. Acceso en: 5 mayo 2017.

MAINGUENEAU, Dominique (2013). Écrivain et image d'auteur. In: DELORMAS, Pascale; MAINGUENEAU, Dominique; ØSTENSTAD, Inger (Ed.). Se dire écrivain: pratiques discursives de la mise en scène de soi. Paris: LambertLucas, p. 13-28.

MEIZOZ, Jerome (2007). ¿Que entendemos por “postura"? In: MEIZOZ, Jerome. Postures littéraires: mises en scène modernes de l'auteur. Traducción de Juan Zapata. Ginebra: Slatkine Érudition, p. 15-32.

NORA, Pierre (Ed.) (1987). Essais d'ego-histoire. Paris: Gallimard.

PRON, Patricio. Rodrigo Fresán contra el fin de la literatura en "La parte inventada". ABC Cultura, Madrid, 17 mar. 2014. Disponible em: <goo.gl/awJxhJ>. Acceso en: 5 mayo 2017.

SAAVEDRA, Carola (2012). Nada é verdade, nada é mentira. Jornal Rascunho, Curitiba, n. 144, abr. Disponible em: <http://rascunho.com.br/nada-e-verdadenada-e-mentira/>. Acceso en: 5 mayo 2017.

SIBILIA, Paula (2008). La intimidad como espectáculo. Buenos Aires: Fondo de Cultura Económica.

TEZZA, Cristovão (2012). O espírito da prosa: uma autobiografia literária. São Paulo: Record.

Recebido em 7 de novembro de 2016.

Aprovado em 8 de novembro de 2017.

\section{resumo/abstract/resumen}

\section{O eu-autor-escritor contemporâneo}

Everton Vinicius de Santa

Esta reflexão se refere à figura do autor, uma vez esta figura se translada para o meio digital, ou seja, para um espaço onde se pode observá-la de modo permanente. Essa passagem ao meio digital implica algumas mudanças na constituição de sua imagem autoral por parte do escritor, ou seja, por parte da pessoa física, do indivíduo que escreve, "o escrevente", segundo Roland 
Barthes. Essa passagem ao meio digital está deslegitimando a figura do autor de nossos dias e, por isso, mudando o papel do escritor contemporâneo. Assim, a reação por parte do escritor reside em sua espetacularização. Discuto esta problemática a partir do conceito de ego-histórias, experiências pessoais presentes no texto em primeira pessoa, a partir algumas características presentes em duas narrativas: O espírito da prosa (2012), de Cristovão Tezza, e La parte inventada (2014), de Rodrigo Frésan. Evidencio, assim, como os meios digitais, a cultura digital e midiática em geral favorece uma reflexão metaliterária sobre a invenção de um eu-autor-escritor que satisfaz a necessidade do exibicionismo alimentado pelos meios digitais na constituição de uma imagem própria.

Palavras-chave: autoria, meios digitais, espetacularização, autoficção.

\section{The contemporary self-author-writer}

\section{Everton Vinicius de Santa}

This article examines how the the author's figure changes once it becomes part of a digital space where this figure can be accessed continuously. This switchover implies some changes in the constitution of the writer's authorial image, or image of the individual who writes, "l'écrivant", according to Roland Barthes. The switch to a digital medium delegitimizes the figure of the contemporary author and, therefore, changes his/her role. Thus, the writer's reaction is to create a spectacle. Using the the concept of "ego-historias", personal experiences present in the first-person text, I discuss this theme on hand of some characteristics present in two narratives: O espirito da prosa (2012), by Christopher Tezza, and La parte inventada (2014), by Rodrigo Fresán. I demonstrate how digital media and digital and media culture in general favor a metaliterary reflection on the invention of a self-author-writer who deals with the need for exhibitionism powered by digital media in the constitution of its own image.

Keywords: authorship, digital media, spectacularization, autofiction.

\section{El yo-autor-escritor contemporáneo}

Everton Vinicius de Santa

Esta reflexión se refiere a la figura del autor una vez que esta figura se traslada al medio digital, esto es, a un espacio donde se puede mirárselo de forma permanente. Ese traslado impone algunos cambios en la elaboración de una entidad autorial por parte del escritor, o sea, la persona física, el individuo que escribe, "l'écrivant", según Roland Barthes. Este paso al medio digital está 
deslegitimando la figura del autor de nuestros días y, por ende, cambiando el role del escritor contemporáneo. Así, la reacción por parte del escritor está siendo su espectacularización. Discuto este tema desde el concepto de egohistorias, experiencias personales en el texto en primera persona, por medio de algunas características presentes en dos narrativas: O espírito da prosa (2012), de Cristovão Tezza, y La parte inventada (2014), de Rodrigo Frésan. Busco evidenciar cómo los medios digitales, la cultura digital y mediática en general favorecen una reflexión metaliteraria sobre la invención de un "yo-autor-escritor" que satisface la necesidad del exhibicionismo que los medios digitales proporcionan en la construcción de su imagen.

Palabras clave: autoría, medios digitales, espetacularización, autoficción.

El presente artículo ha sido realizado con el apoyo del Conselho Nacional de Desenvolvimento Científico e Tecnológico (CNPq) y de la Coordenação de Aperfeiçoamento de Pessoal de Nível Superior (Capes) - Brasil. 